\section{SURGERY IN THE CONGO}

BY

\section{B. W. FOX, F.R.C.S., F.R.C.S.Ed., F.R.A.C.S.}

Surgical Registrar, Postgraduate Medical School, Hammersmith Hospital, London; formerly Surgeon to Australian Red Cross Field Force, Congo

Under the Belgian colonial administration the medical services for the Belgian Congo were very good. However, all the doctors were Belgian and all important administrative posts were filled by Belgians, so that after their precipitate departure in July, 1960, all medical control completely collapsed.

Added to this was the outbreak of savage intertribal warfare that had previously been held in check by the Belgian colonial forces. As a result many native medical assistants and orderlies were forced to flee for their lives from their place of employment to their own hereditary tribal areas. Many of them were slaughtered by marauding tribesmen in the hospitals or en route. There was a lack not only of trained medical personnel but also of public health inspectors, sanitary engineers, electricians, and motor mechanics. In fact, the country was in total chaos.

\section{Battle Casualties}

My first introduction to this turmoil was in the mining town of Bakwanga, in the centre of the Congo bushland. The Australian medical team arrived on the second day of heavy fighting between Federal Government troops and rebel soldiers of the secessionist " mining state." Both sides were armed with the latest weapons and light artillery.

Being without much equipment of our own, we made use of whatever facilities we could find and scavenge. We set up in the beleaguered native hospital of Disele and began work immediately. The hospital was formerly owned by the Forminiere Mining Company and was superbly equipped for a native workers' hospital, except that now there were no orderlies, no water, and no electricity or food.

Operations were performed under sweltering conditions in swim trunks only, with bare hands soaked in alcohol-iodine and instruments sterilized by boiling in water carried by hand from a well some 300 yards (275 metres) away. The thing that impressed me most was the fortitude of the Congolese, both civilians and soldiers, rebel and Government alike. Despite the most horrible shrapnel wounds, bullet wounds (Fig. 1), bayonet or spear wounds, and burns, they were incredibly courageous and would lie quietly on the ground awaiting their turn to be operated on. Even the smallest children (Fig. 2) rarely cried or complained. Also it must be pointed out that most procedures were carried out under local or spinal anaesthesia because we lacked sufficient general anaesthetic.

Chest wounds presented an interesting feature here. At this hospital I treated four cases of penetrating wounds of the chest-two bullet wounds, one bayonet wound, and one shrapnel injury. In none of these cases had the lung collapsed, so that it was possible to carry out a debridement of the wound and a limited exploration of the lung, and securely close the chest under local anaesthesia. The reason for this is the high incidence of pulmonary tuberculosis among the
Congolese and the numerous adhesions between the visceral and parietal pleura which prevent the lung from collapsing.

All patients, and often their relatives, invariably demanded to be shown the bullets or shrapnel that had been removed. This stems from the belief of the natives that they cannot recover from a bullet wound unless the missile is removed. In many instances this was neither advisable nor expedient ; consequently I collected every possible type of missile. These were kept in the operating-theatre, and by careful pre-operative interrogation we endeavoured to determine what type of

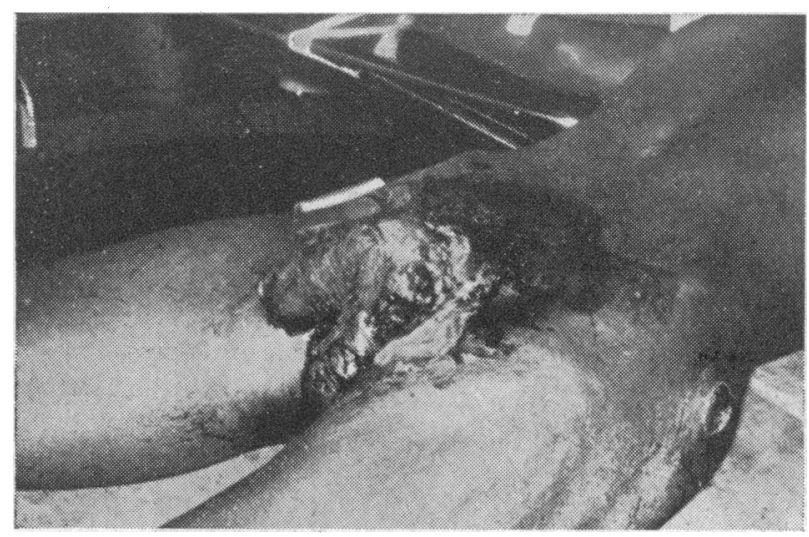

Fio. 1.-Ruptured urethra from bullet-wound during fighting at Bakwanga.

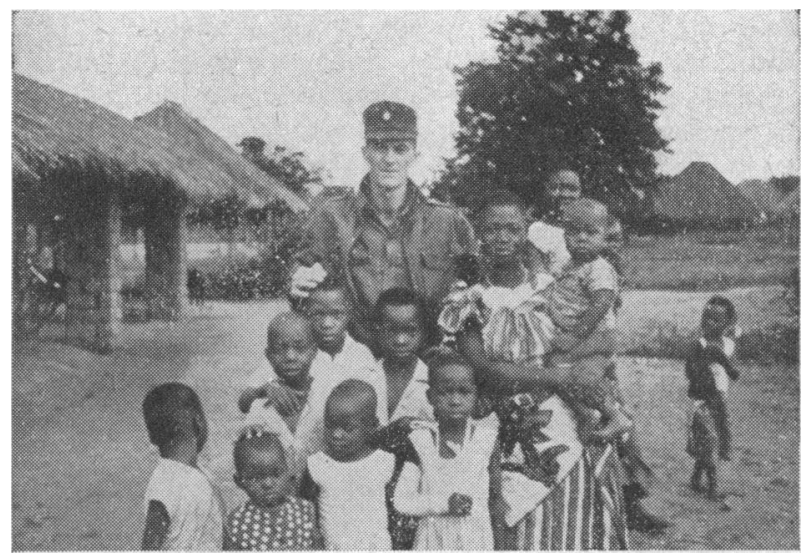

Frg. 2- - Out-patient work in a village. The child in the fore ground had a supracondylar fracture of the right humerus.

weapon had inflicted the injury, and we were always able to produce a similar bullet, from those of the latest automatic weapons to the lead ball of the primitive tribesman's muzzle-loader.

One unfortunate feature of our work here was that the Government soldiers had set up their heavy mortars on the front lawn of one of our hospitals, and thus wounded civilians were afraid to approach the building for treatment as they would have to pass through these entrenchments. It was only after two days of vigorous remonstration with the local commandant that we persuaded the mortar batteries to move, and more and more wounded civilians then arrived at this hospital. As many of the civilians that we had not rescued ourselves from devastated villages did not arrive at the hospital for some four or five days after being wounded, their wounds were invariably grossly infected and covered with maggots. 


\section{A Medical Practice of 300,000 Tribesmen}

After several weeks in the Bakwanga area the fighting subsided, and, accompanied by an extremely capable R.A.A.M.C. sergeant, I was sent to the small town of Luiza, on the Kasai-Katanga border some 80 miles (128 $\mathrm{km}$.) from the Portuguese colony of Angola. This was the real primitive Africa-a land of tom-tom drums, large tracts of dense bush, crocodiles, and hippopotami.

Although Luiza was the administrative capital for a huge area, apart from the hospital, a small Government administrative building, and five native shops, the town merely consisted of dozens and dozens of native mud huts (Fig. 3) scattered in some 12 villages about the hospital. The population consisted of four Belgian Catholic nuns, one Italian builder, one Indian, and some 6,000 tribesmen. The nearest doctor was 200 miles $(320$ $\mathrm{km}$.) away, and we were informed by the local Congolese administration that our hospital now provided the only doctor for a native population of 300,000 people.

The Luiza hospital was a native hospital constructed in 1954 by the Belgian administration, and had a total of 250 beds, including the medical, surgical, maternity, and tuberculosis sections. In addition this hospital maintained and administered four small rural dispensaries (out-patient clinics) at Tende, Yao, Kabaluku, and Kavueta, which were villages situated 60 to 90 miles (96 to $145 \mathrm{~km}$.) in a circle around the hospital.

Before June 30, 1960 (independence of the Republic of Congo), the Luiza hospital staff consisted of : one European doctor, four trained European nurses (Catholic nuns), one Congolese assistant médical, one Congolese infirmier, 15 Congolese aides infirmiers (who included one aide infirmier at each of the four rural dispensaries), two Congolese assistant midwives, one European agent sanitaire, one Congolese hospital secretary, and one hospital mechanic to maintain the important diesel motor.

There was a very limited supply of drugs in the pharmacy, and the hospital diesel motor was broken and had not been running for three months. As a result there was no water or electricity supply for the hospital. The $x$-ray machine was out of order.

Several intelligent young Congolese young men were recruited and taught to administer certain drugs and how to change dressings in the wards. By enticing some orderlies away from neighbouring hospitals that had no doctor and were doing little work, the hospital staff gradually returned to almost its normal establishment. Then, with motor parts and diesel oil bought, begged, and stolen from here and there, it was eventually possible to restart the battered motor, thus ensuring a supply of water and electricity, and rapidly the Luiza hospital became a thriving concern.

\section{Surgery at Luiza}

The Luiza territory had not been devastated by the fighting that had occurred in many other parts of the country, so that the surgery done there does give an indication of the ordinary surgical problems to be encountered in the Republic of Congo. Most of the traumatic surgery seen in this region was the result of hunting accidents or machete fights after drinking-bouts in the villages. Over 400 minor surgical and obstetrical procedures were carried out in the four and a half months $I$ was at this hospital, but these are not included in the analysis of operations given in Table I.

TABLE I.-Analysis of 332 Major Surgical Operations at Luiza Hospital Between September 23, 1960, and February 1, 1961

Operation for hernia

Laparotomy: (1) diagnostic for abdominal pain, (2) tuberculous peritonitis, (3) tuberculous glandular mass, (4) evacuation of tuberculous abscesses, (5) drainage of pelvic abscesses

Small-bowel resection

Partial resection of large bowel

Untwisting of volvulus of sigmoid colon

Total hysterectomy.

Subtotal hysterectomy

Excision of cyst of Gartner's duct

Caesarean section

Enucleation of fibroids

Subtotal thyroidectomy

Skin grafts

Excision of masses about neck: (1) tuberculous glands, (2) chronic infection of submandibular gland, (3) parotid abscess.

Salpingo-oophorectomy for ovarian cyst, pyosalpinx

Manchester repär " ruptured ectopic pregnancy

Plastic operation on the hand (other than grafts). .

Anteversion operations (Crossen-Gilliam and Baldy-Webster)

Appendicectomy

Closure and drainage of open wounds of thorax

Debridement and suture of other bullet wounds of limbs and face

Operations for compound fractures

Nephro-uret" simple fractures

Splenectoreterectomy

Excision of chronic hydrocele

Enucleation of eye .

Throughout the Congo the incidence of inguinal hernia is very high. It is usual for a surgeon in a rural hospital to perform four or five herniorrhaphies each day. $80 \%$ of the inguinal hernias occur in men of 35 to 40 , and the indirect hernia is more common than the direct type. Various explanations have been advanced to explain the frequency of inguinal hernia in these people. I was not able to substantiate the view held by some surgeons there that the external and internal inguinal rings are closer together in the Congolese than in the whites, nor can the high incidence be ascribed to weak abdominal musculature, since most patients on whom I operated had very well developed abdominal muscles (Table II).

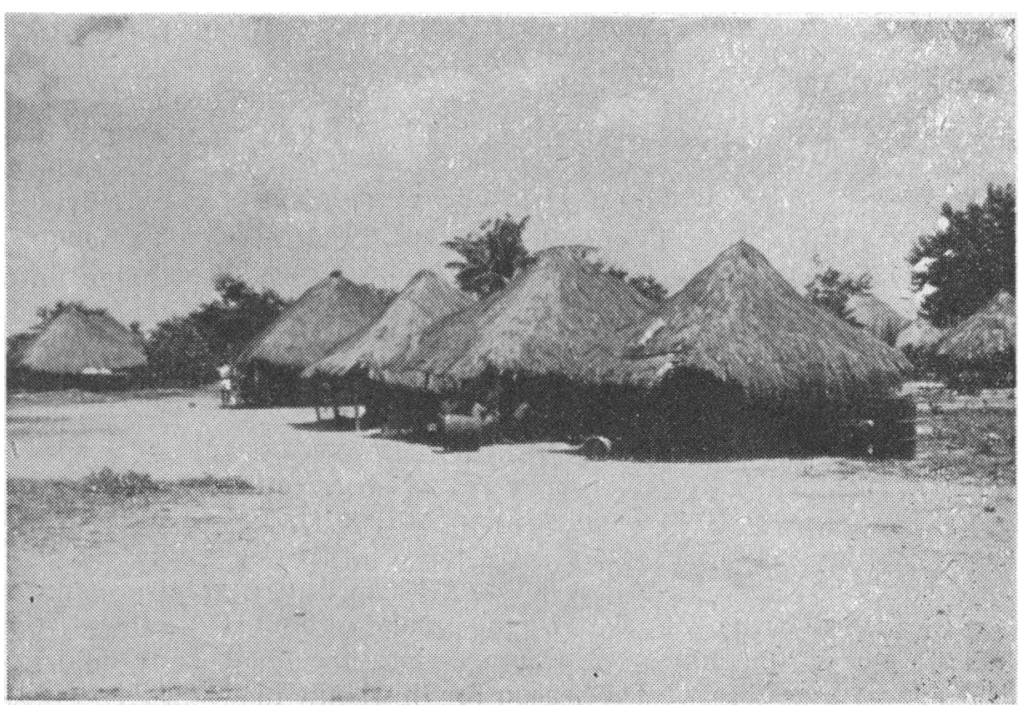

FIg. 3.-Mud huts at Luiza. 
TABLE II.-Analysis of the 116 Operations for Hernia at Luiza Simple hernia:

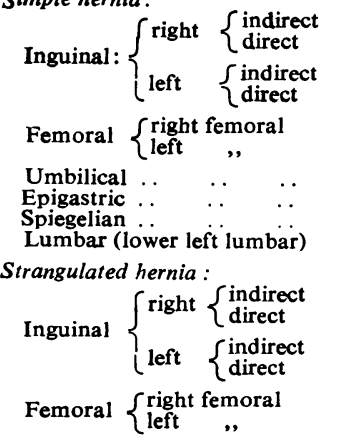

A most significant feature, however, was that nearly all these people had some coincidental chronic abdominal condition such as cirrhosis, splenomegaly, and ascites (due to portal hypertension, chronic peritoneal tuberculosis, or nutritional deficiency). All these conditions produce an increase in the intra-abdominal pressure, and, particularly in the presence of a congenital sac, this often leads to a herniation of abdominal contents. It was quite common to open the hernial sac and be greeted by a flood of amber-coloured fluid looking suspiciously like urine, only to find that it was ascitic fluid that had not been clinically detectable. A case of lumbar hernia is illustrated (Fig. 4).

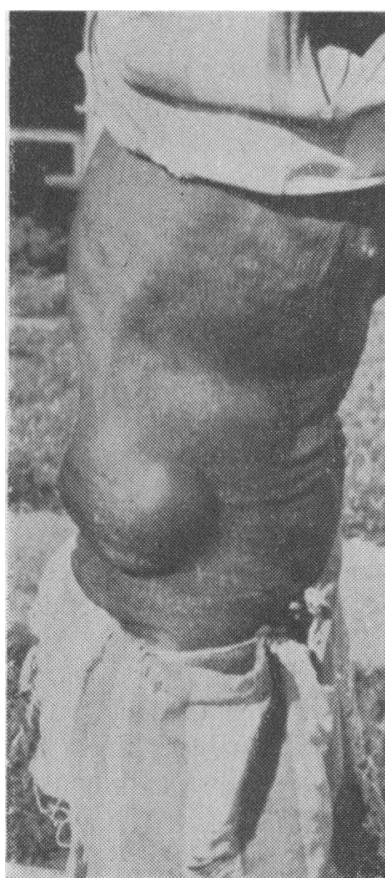

(a)

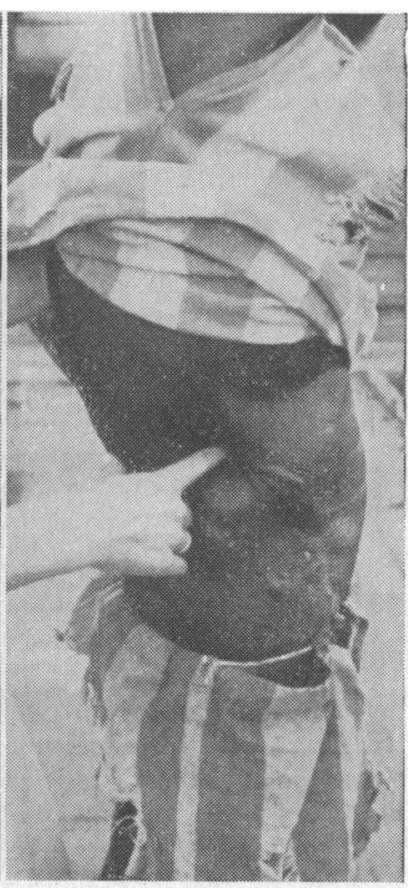

(b)
Fig. 4.-Case of lumbar hernia: $(a)$ before reduction; $(b)$ after reduction.

Because of the high incidence of hernia and the ignorance of this primitive population many of the more bizarre complications were seen. Perhaps the following case will serve to illustrate this.

Case History.--In March, 1960, a Congolese woman aged approximately 40 experienced a sudden onset of generalized abdominal pain together with the appearance of a tender lump in the left groin. The pain persisted for several days, during which time she began to vomit and did not open her bowels. On the seventh day the swelling in the groin burst and discharged copious amounts of yellow semi-solid material. After this she felt much improved. From then on her bowels did not open and she continued to discharge this material from the opening in the groin. In May, 1960, she presented at a tiny rural dispensary and was treated by the Congolese orderly with antibiotics in the belief that she had a discharging bubo from lymphogranuloma inguinale, which is quite common in this region. When she was seen at Luiza Hospital in October, 1960, it was obvious that she had a faecal fistula, probably due to the ulceration through the skin of a strangulated femoral hernia. The patient was emaciated and could walk only with help. Laparotomy confirmed the diagnosis. The terminal ileum was incarcerated in the left femoral canal, and the small intestine above the hernia was hypertrophied but not dilated, while the bowel distal to the fistula was collapsed and did not contain faeces. After resection of the involved ileum and a femoral herniorrhaphy, the patient made a rapid recovery.

Umbilical hernia is commonly seen in the villages, although few appear to give symptoms (despite their massive size), and thus the people with this condition do not come to the hospitals for surgery. After childbirth in the villages the umbilical stump is often smeared with mud and goat dung, which produces a raw, infected umbilical region and a scarred area in the anterior abdominal wall which subsequently attenuates and results in an umbilical hernia.

\section{Gynaecology}

Operations for gynaecological problems feature high on the list of surgical work in the Congo. Neglected ovarian cysts and fibroids of immense size were exceedingly common. Many of the villagers with large ovarian cysts were convinced they were pregnant and waited for several years for babies that never arrived.

Venereal disease, particularly gonorrhoea, was very common, so that inflammation of the uterus and adnexae with its legacy of dense adhesions made operations in the pelvis rather hazardous. Since I had no facilities for cystoscopy and ureteric catheterization, in several cases I was forced to be content with a subtotal hysterectomy despite my surgical training about the risks of leaving the cervix behind.

As will be seen from Table I, caesarean section was often performed. The indication in each case was either disproportion-a small pelvis and a large baby-or a history of previous caesarean section. When it is remembered that many of the Congolese have their first child when about 15 years of age it will be realized how frequently obstructed labour can occur. Many of the women I operaied on had had previous caesarean sections, and, though it is possible that some of these were performed by Congolese medical assistants or male nurses in the more remote regions without proper indications being present, nevertheless caesarean section had to be done again.

\section{Burns and Skin Grafts}

Epilepsy is not uncommon among the Congolese, and may be idiopathic or the aftermath of syphilis, encephalitis, cerebral malaria, or birth trauma. Epileptiform convulsions occurring while the native is crouching around his fire frequently result in burns. Burns of $5-6 \%$ of the surface area were commonly seen, but, fortunately, no burn larger than $10 \%$.

The village witch-doctors were responsible for the other superficial burns we had to treat (Fig. 5). I came to know some of these "doctors" quite well and learned much about their "art." A villager complaining of pain in some region of his body may be treated 
by the witch-doctor in one of two main ways. There were several other little tricks, but the following were the two most commonly encountered. Firstly, he may give his patient some dreadful corrosive concoction to swallow, but more often he prefers to apply boiling palm-oil to the skin over the painful region so that the excruciating superficial pain of the burn causes the

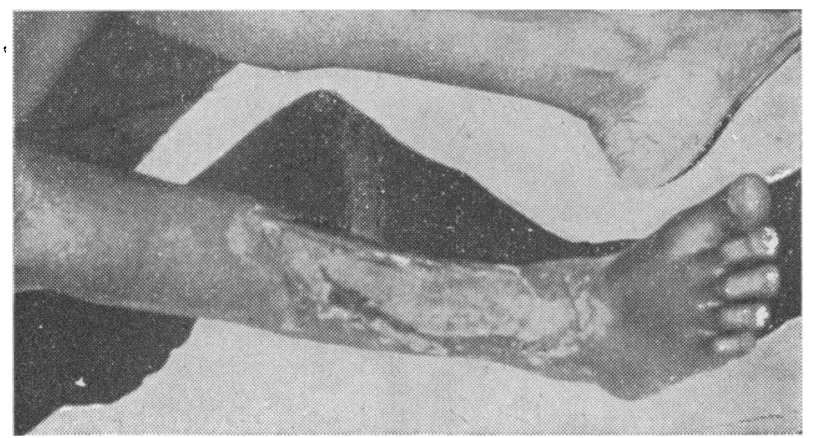

Fig. 5.-Burns on leg resulting from witch-doctor's medicine.

patient to forget his previous internal malady. The more skilled performer may make 20 to 30 tiny subcutaneous cuts about the tender area and then smear into these a tarry abrasive paste. Both these methods eventually lead to a sloughing of the skin and an angry infected raw area which it is necessary to cover by skin graft.

With half a safety-razor blade held in a Kocher forceps as a skin knife, split-skin postage-stamp grafts were used on many occasions and, surprisingly, almost invariably survived in their entirety despite the presence of pus about the site to be grafted. Plastic surgery is particularly heart-breaking among these primitive people, as they will insist on removing the bandages or just leaving the hospital after operation and making off into the jungle for five or six days, then returning and expecting continuation of their treatment. It was impossible to refuse these delightful people treatment, and often we would follow an absconcer 30 to 40 miles $(48-64 \mathrm{~km}$.) to his village and persuade him that it was in his interest to return.

\section{Laparotomy for Diagnosis}

The Congolese are great hypochondriacs and marvellous actors, with a passionate desire to be operated on. Thus the phrase "Munganga koopanda doosama bicola" (Doctor, operate, I have terrible pain), accompanied by very realistic writhing motions and contortions, made a very convincing picture of some abdominal catastrophe even in the absence of definite physical signs. In my early days among these people, with a poor appreciation of their mentality, a limited grasp of the Tshiluba language, and the absence of any diagnostic facilities, when presented with someone in such "obvious" pain I felt obliged to perform a laparotomy despite the absence of definite physical signs. After three or four unnecessary laparotomies I became more discerning.

All forms of tuberculous involvement of the peritoneum, mesenteric glands, intestine, and even of the liver were seen. Abdominal tuberculosis was extremely common, and accounted for many of the cases of vague abdominal pain.

Anaesthesia and Resuscitation

In the absence of any general anaesthetic we were forced to do all operations under local or spinal anaes- thesia. Local infiltration of the region with lignocaine was used for simple hernia, caesarean section, and operations about the head and neck.

Spinal anaesthesia was used in all other cases. For a person little versed in the art of anaesthesia I must confess that I entered upon the field of spinal anaesthetics with some trepidation. Heavy cinchocaine was used, $2.5 \mathrm{ml}$. being introduced each time, and for upper abdominal work, such as splenectomy, anaesthesia could be obtained up to T 4 level without difficulty. Spinal anaesthesia was given on more than 200 occasions without untoward complications.

In such a remote area resuscitation was quite a problem. On arrival at Luiza I determined the ABO blood groups of the hospital employees and all the prisoners in the local gaol as potential donors. There were problems, however, in that these people have an aversion to giving blood to people they do not know, and also, as a result of malaria, chronic malnutrition, etc., many of these people had a haemoglobin of $60 \%$ or less and were not suitable for use as donors. An inducement of 100 francs for 1 litre of blood did provide an adequate number of donors when the need arose.

In the case of ruptured ectopic pregnancy and haemoperitoneum the blood was scooped out of the peritoneal cavity with a sterile teacup, citrated in a bowl, strained through gauze to remove any clots, and infused back into the patient. This procedure was performed on three occasions without trouble.

In 42 blood transfusions (for medical and surgical cases), despite the fact that only $\mathrm{ABO}$ grouping and a thorough clinical examination of the donor were carried out, no transfusion reactions occurred.

\section{Interesting Anomalies}

Pre-auricular Sinus.-I observed eight people with pre-auricular sinus. This appears to be common in this region. In only two cases was the sinus bilateral and in only one case was I able to detect the presence of a mole immediately anterior to the sinus. One case had multiple secondary sinuses with a past history of recurrent infection, but all the other cases were symptomless.

Accessory Digits.-Another anomaly encountered there was the frequent presence of an accessory digit on the ulnar aspect of the little finger. I saw this condition in six people, and in four of them there was an accessory finger on both hands. This sixth digit usually grows from the middle phalanx of the little finger and varies in its degree of development from a rudimentary horn of several millimetres to a mature finger of one or two phalanges. There is always a nail present. The three adults I saw with this accessory digit refused amputation as they regarded it as a good-luck sign.

\section{Conclusion}

I hope that this rather discursive commentary will illustrate the types of surgical problems to be encountered in the Congo and the urgent requirement for more medical personnel in this new country.

I thank Professor Ian Aird, of the Department of Surgery, Postgraduate Medical School, Hammersmith Hospital, London, for the help he has given me in writing this article, and Professor Maurice Ewing, of the Department of Surgery, University of Melbourne, who made it possible for me to go to the Congo. 